\title{
Effect of Air Abrasion on the Marginal Configuration of Titanium Crowns after Casting
}

\author{
Bhupender Yadav, Puja Malhotra, Ramesh Nadiger, Harish Yadav
}

\begin{abstract}
The present study was carried out to evaluate and compare the effect of air abrasion on marginal accuracy of titanium crowns after casting. A total of 90 samples were prepared which were divided in three groups of 30 specimens each of shoulder, chamfer and shoulder with bevel marginal configurations respectively. Thirty samples were air abraded using $120 \mu \mathrm{m}$ particle size of aluminum oxide particle and remaining 30 specimens by $250 \mu \mathrm{m}$ particle sizes respectively. The length from the reference line and tip of the cast specimens before and after sand blasting was measured with the help of traveling microscope. Same specimens were subjected to trimming for removal of alpha case layer for a standardized time, speed and pressure. The basic data of marginal discrepancy due to sand blasting and alpha case removal for each marginal configuration were evaluated and compared with data for the control group using student ' $t$ ' test and ANOVA. The smaller the margin angle, the greater was the loss of alloy after air abrasion (shoulder with bevel > chamfer > shoulder). Particle size of the abrasive also influenced the vertical marginal loss, as the particle size increased from 120 to $250 \mu \mathrm{m}$, marginal loss also increased. Finishing of casting margins after sandblasting also induced vertical marginal loss.
\end{abstract}

Keywords: CP grade II titanium, Air abrasion, Aluminum oxide.

How to cite this article: Yadav B, Malhotra P, Nadiger R, Yadav $\mathrm{H}$. Effect of Air Abrasion on the Marginal Configuration of Titanium Crowns after Casting. Int J Prosthodont Restor Dent 2013;3(4):131-135.

\section{Source of support: Nil}

Conflict of interest: None

\section{INTRODUCTION}

Air abrasion of castings for metal ceramic crowns is a routine procedure in dental ceramics laboratories to remove retained phosphate bonded investment material. ${ }^{1}$ Air abrasion is commonly called as 'sand blasting', 'microabrasion' and 'particle abrasion'. Air abrasion has been recommended for the removal of oxides from the metallic surfaces, preparation of internal casting surfaces for cementation, removal of disclosing media used during fitting procedures, removal of investment during casting recovery, creation of irregularities in internal casting surfaces prior to micromechanical bonding, ${ }^{2}$ preparation of metal surfaces for porcelain application to increase the wettability of the metal surfaces. ${ }^{3,4}$

The commonly used materials for sand blasting are carborundum, aluminum oxide and glass beads. ${ }^{5}$ Air abrasion of the restorations has the potential to remove significant amount of material and the thin margins on the casting may be altered or significantly worn which could affect the clinical adaptation of the restorations. ${ }^{6}$ Titanium is increasingly gaining acceptance for fabrication of metallic substructure for crown and bridge and implant prosthesis because of its good biocompatibility and the attractive mechanical properties, including the light weight, strength to weight ratio, high ductility, and low thermal conductivity. ${ }^{7}$ As the dental literature lacks in this aspect of the effect of mechanical treatment such as air abrasion and finishing on marginal accuracy of cast titanium structure, this study is intended to evaluate the marginal discrepancy due to air abrasion and finishing on titanium casting margin having different marginal ${ }^{3}$ configurations, and also to publicize the risks of damage of these mechanical treatment to the dentists and to the laboratory technician's community.

\section{MATERIALS AND METHODS}

To test the effect of air abrasives in a reproducible manner, three Standardized rectangular stainless steel dies measuring $20 \mathrm{~mm}$ in length, $8 \mathrm{~mm}$ in width and $3 \mathrm{~mm}$ in thickness were milled on one side, using a rotary lapping machine (Leco VP 160, Leco corporation) to simulate a $3 \mathrm{~mm}$ section through the axial surface of a cast crown. Separate dies were milled to produce chamfered, shoulder and shoulder with bevel margin configurations (Fig. 1). Each die was used as a master model for the production of castings using several different types of alloys. Impressions were made of each die by use of a vinyl polysiloxane impression material. Duplicate patterns were made from inlay casting wax (schuller-dental ULM-W, Germany). A reference line

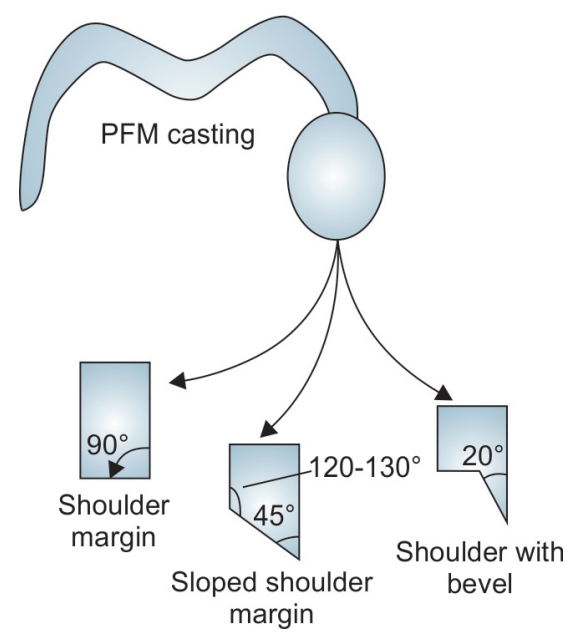

Fig. 1: Margin configurations evaluated for alloys 
was marked on the wax pattern just below the area of sprue attachment on the external surface of the casting; three points were marked on this reference line to aid in pre and post test measurement of the samples. The patterns were sprued, invested in phosphate bonded investment and casted in commercially pure titanium grade 2 . The angles at the margins were 20,45 and $90^{\circ}$ to represent shoulder with bevel, chamfer, and shoulder designs, respectively. Ninety castings, 30 for each margin configuration, were made to test each abrasive. Completeness of castings and maintenance of marginal angles were verified with a light microscope at $\times 200$ magnification.

The 90 samples were divided into two groups, i.e. group 1 (60 samples) and group 2 (30 samples). Group 1 was further divided into two groups A and B; Group 1A was sandblasted with 120 microns $\mathrm{Al}_{2} \mathrm{O}_{3}$ whereas group $1 \mathrm{~B}$ was sandblasted with 250 microns $\mathrm{Al}_{2} \mathrm{O}_{3}$. Group $1 \mathrm{~A}, 1 \mathrm{~B}$ and group 2 were further subdivided into three subgroups of 10 samples each, i.e. a (shoulder with bevel margin), b (chamfer margin) and c (shoulder margin). Group II (control group) having 30 specimens (i.e. 10 each of each marginal configuration) were immersed in acid solution to remove the investment material.

Group 1A samples were air abraded using $120 \mu \mathrm{m}$ particle size of aluminum oxide particles and group $1 \mathrm{~B}$ specimens by $250 \mu \mathrm{m}$ particle size of aluminum oxide particle respectively. All castings were abraded by use of a straight round nozzle with the microtip of the air abrasion unit $1 \mathrm{~cm}$ from the casting margin and the abrasive directed at the external marginal surface.

The conditions of nozzle type, nozzle diameter, and pressure were consistent with the manufacturer's suggestions for cleaning, deburring and light-to-medium cutting with aluminum oxide particles. A sweeping motion of the microtip was used to ensure uniform abrasion over the entire casting surface. Each abrasion time was measured with a stopwatch. After abrasion the castings were cleaned with compressed air to remove any remaining particulate material. The time was kept constant at $15 \mathrm{sec}$ and pressure at 4 bars. The length from the reference line and tip of the cast specimens before and after sandblasting were measured with the help of travelling microscope. This data was used for calculating the marginal discrepancy.

Same specimens were subjected to trimming for removal of alpha case layer for removal of alpha case layer and the resultant marginal discrepancy was measured using traveling microscope. The basic data of marginal discrepancy due to sandblasting and alpha case layer removal for each marginal configuration was evaluated and compared with data for the control group using student ' $t$ ' test and ANOVA.

Attempts were made to standardize the machinery and the procedures throughout the study to minimize the effect of variable factors on the observations and the final results. This standardization also helped to predict the clinical performance of the various materials used and to improve the success of this in vitro study. The various factors considered for standardization included sample preparation, air abrasion of sample and the direction, magnitude and frequency of the applied load during finishing of samples to remove alpha case layer.

\section{RESULTS}

The marginal loss due to air abrasion in various margins was calculated in micrometers. Statistical analysis, using the unpaired ' $t$ '-test was done. The calculated mean, standard deviation and ' $t$ ' test comparison of different groups and

Table 1: Pairwise comparison of three groups [group 1A(a), group
$\begin{aligned} & \text { 1A(b), group } 1 \mathrm{~A}(\mathrm{c}) \text { ] } \\
& \text { microns aluminum oxide by unpaired t-test }\end{aligned}$
\begin{tabular}{lllll}
\hline Groups & Mean & $S D$ & $t$-value & $p$-value \\
\hline Group 1A(a) & 100 & 29.0593 & 5.2333 & $0.0001^{*}$ \\
Group 1A(b) & 51 & 5.6765 & & \\
Group 1A(a) & 100 & 29.0593 & 8.8309 & $0.0000^{*}$ \\
Group 1A(c) & 18 & 4.2164 & & \\
Group 1A(b) & 51 & 5.6765 & 14.7580 & $0.0000^{*}$ \\
Group 1A(c) & 18 & 4.2164 & & \\
\hline
\end{tabular}

*Significant value

Table 2: Pairwise comparison of three groups [group $1 \mathrm{~A}(\mathrm{a})$, group $1 A(b)$, group $1 A(c)$ ] marginal loss after finishing (removal of alpha case layer) by unpaired t-test

\begin{tabular}{lllll}
\hline Groups & Mean & $S D$ & t-value & $p$-value \\
\hline Group 1A(a) & 21 & 7.3786 & 2.8685 & $0.0102^{*}$ \\
Group 1A(b) & 13 & 4.8305 & & \\
Group 1A(a) & 21 & 7.3786 & 3.9392 & $0.0010^{*}$ \\
Group 1A(c) & 11 & 3.1623 & & \\
Group 1A(b) & 13 & 4.8305 & 1.0954 & 0.2878 \\
Group 1A(c) & 11 & 3.1623 & & \\
\hline
\end{tabular}

*Significant value

Table 3: Pairwise comparison of three groups [group $1 \mathrm{~B}(\mathrm{a})$, group $1 \mathrm{~B}(\mathrm{~b})$, group $1 \mathrm{~B}(\mathrm{c})]$ marginal loss after sandblasting with 250 microns aluminum oxide by unpaired t-test

\begin{tabular}{lllll}
\hline Groups & Mean & $S D$ & $t$-value & $p$-value \\
\hline Group 1B(a) & 144 & 6.9921 & 23.3314 & $0.0000^{*}$ \\
Group 1B(b) & 69 & 7.3786 & & \\
Group 1B(a) & 144 & 6.9921 & 39.6769 & $0.0000^{*}$ \\
Group 1B(c) & 31 & 5.6765 & & \\
Group 1B(b) & 69 & 7.3786 & 12.9080 & $0.0000^{*}$ \\
Group 1B(c) & 31 & 5.6765 & & \\
\hline
\end{tabular}

*Significant value

Table 4: Pairwise comparison of three groups [group $1 \mathrm{~B}(\mathrm{a})$, group $1 \mathrm{~B}(\mathrm{~b})$, group $1 \mathrm{~B}(\mathrm{c})]$ marginal loss after finishing (removal of alpha case layer) by unpaired t-test

\begin{tabular}{lllll}
\hline Groups & Mean & $S D$ & $t$-value & $p$-value \\
\hline Group 1B(a) & 19 & 7.3786 & 1.0534 & 0.3061 \\
Group 1B(b) & 16 & 5.1640 & & \\
Group 1B(a) & 19 & 7.3786 & 2.6047 & $0.0179^{*}$ \\
Group 1B(c) & 12 & 4.2164 & & \\
Group 1B(b) & 16 & 5.1640 & 1.8974 & 0.0739 \\
Group 1B(c) & 12 & 4.2164 & & \\
\hline
\end{tabular}

*Significant value 
Table 5: Pairwise comparison of three shoulder with bevel margin groups [group 1A (a), group 1B (a) and group 2 (a)] marginal loss after sandblasting by unpaired t-test

\begin{tabular}{lllll}
\hline Groups & Mean & $S D$ & $t$-value & $p$-value \\
\hline Group 1A(a) & 100 & 29.0593 & -4.6553 & $0.0002^{*}$ \\
Group 1B(a) & 144 & 6.9921 & & \\
Group 1A(a) & 100 & 29.0593 & 10.5540 & $0.0000^{*}$ \\
Group 2(a) & 2 & 4.2164 & & \\
Group 1B(a) & 144 & 6.9921 & 54.9964 & $0.0000^{*}$ \\
Group 2(a) & 2 & 4.2164 & & \\
\hline
\end{tabular}

*Significant value

Table 6: Pairwise comparison of three chamfer margin groups [group $1 \mathrm{~A}(\mathrm{~b})$, group $1 \mathrm{~B}(\mathrm{~b})$ and group 2(b)] marginal loss after sandblasting by unpaired t-test

\begin{tabular}{lllll}
\hline Groups & Mean & $S D$ & $t$-value & $p$-value \\
\hline Group 1A(b) & 51 & 5.6765 & -6.1143 & $0.0000^{*}$ \\
Group 1B(b) & 69 & 7.3786 & & \\
Group 1A(b) & 51 & 5.6765 & 20.3647 & $0.0000^{*}$ \\
Group 2(b) & 3 & 4.8305 & & \\
Group 1B(b) & 69 & 7.3786 & 23.6655 & $0.0000^{*}$ \\
Group 2(b) & 3 & 4.8305 & & \\
\hline
\end{tabular}

*Significant value

Table 7: Pairwise comparison of three shoulder margin groups [group $1 \mathrm{~A}(\mathrm{c})$, group $1 \mathrm{~B}(\mathrm{c})$ and group $2(\mathrm{c})$ ] marginal loss after sandblasting by unpaired t-test

\begin{tabular}{lllll}
\hline Groups & Mean & $S D$ & $t$-value & $p$-value \\
\hline Group 1A(c) & 18 & 4.2164 & -5.8138 & $0.0000^{*}$ \\
Group 1B(c) & 31 & 5.6765 & & \\
Group 1A(c) & 18 & 4.2164 & 7.3980 & $0.0000^{*}$ \\
Group 2(c) & 3 & 4.8305 & & \\
Group 1B(c) & 31 & 5.6765 & 11.8794 & $0.0000^{*}$ \\
Group 2(c) & 3 & 4.8305 & & \\
\hline
\end{tabular}

*Significant value

Table 8: Pairwise comparison of three groups (group 1A, group 1B and group 2) marginal loss after sandblasting by unpaired t-test

\begin{tabular}{lllll}
\hline Groups & Mean & $S D$ & $t$-value & $p$-value \\
\hline Group 1A & 56.3333 & 38.1000 & -2.2290 & $0.0297^{*}$ \\
Group 1B & 81.3333 & 48.1902 & & \\
Group 1A & 56.3333 & 38.1000 & 7.6619 & $0.0000^{*}$ \\
Group 2 & 2.6667 & 4.4978 & & \\
Group 1B & 81.3333 & 48.1902 & 8.9024 & $0.0000^{*}$ \\
Group 2 & 2.6667 & 4.4978 & & \\
\hline
\end{tabular}

*Significant value

Table 9: Pairwise comparison of three groups (groups 1A, 1B and group 2) marginal loss after finishing by unpaired t-test

\begin{tabular}{lllll}
\hline Groups & Mean & $S D$ & $t$-value & $p$-value \\
\hline Group 1A & 15.0000 & 6.8229 & -0.3943 & 0.6948 \\
Group 1B & 15.6667 & 6.2606 & & \\
Group 1A & 15.0000 & 6.8229 & 8.2663 & $0.0000^{*}$ \\
Control & 2.6667 & 4.4978 & & \\
Group 1B & 15.6667 & 6.2606 & 9.2367 & $0.0000^{*}$ \\
Control & 2.6667 & 4.4978 & & \\
\hline
\end{tabular}

*Significant value

subgroups are given in Tables 1 to 9. On the basis of the observations, the following results were obtained.

The data showed maximum marginal loss in relation to shoulder with bevel margin and minimum loss with

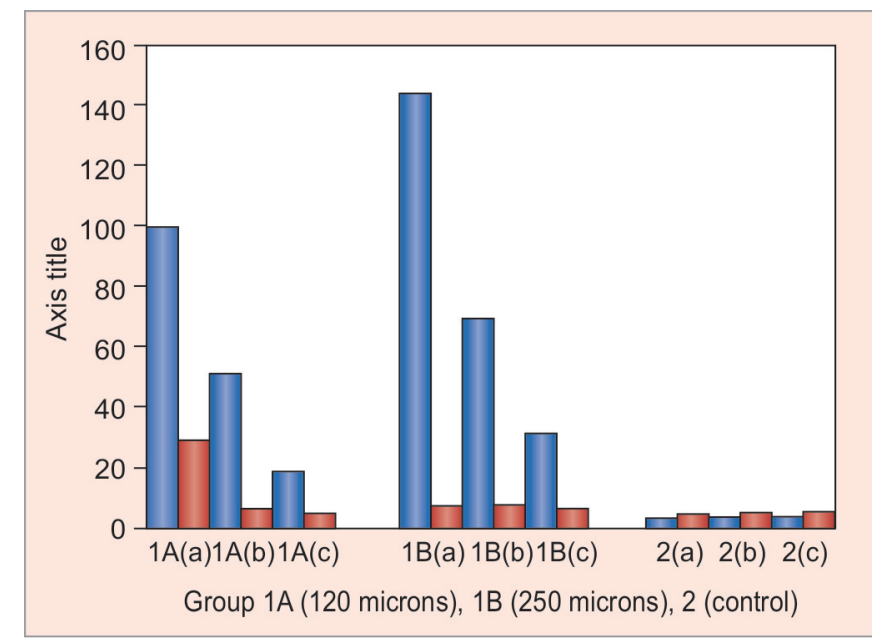

Graph 1: Comparison of three finish lines shoulder with bevel (a) chamfer (b) and shoulder (c) after air abrasion

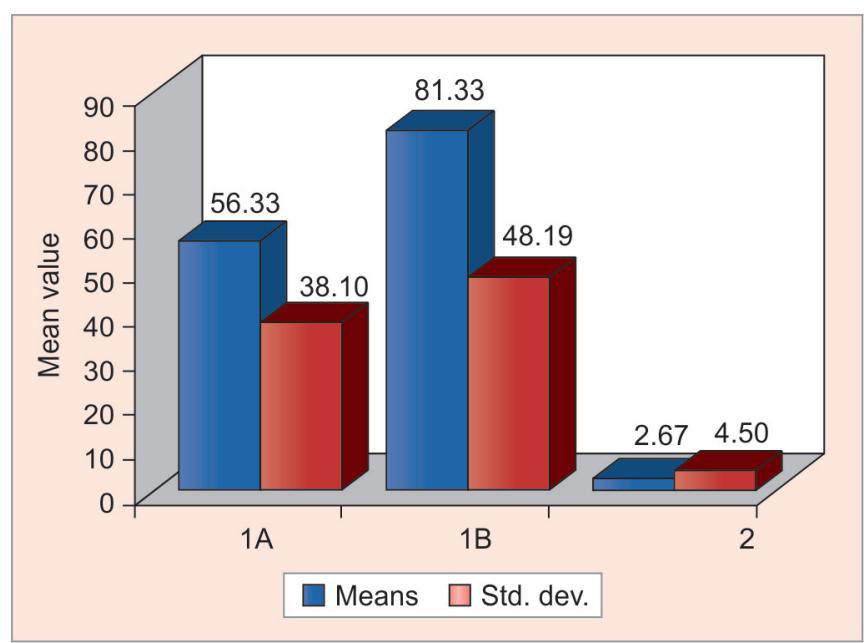

Graph 2: Comparison of groups $1 \mathrm{~A}, 1 \mathrm{~B}$ and group 2 with marginal loss after sandblasting

shoulder edge margin. The difference in marginal loss after air abrasion with 120 and $250 \mu \mathrm{m}$ aluminum oxide showed significant result when compared with ANOVA and student t-test with $\mathrm{p}$-value $0.0000(\mathrm{p}<0.05)($ Graph 1$)$. There was also a statistically significant difference in marginal loss between groups $1 \mathrm{~A}$ and $1 \mathrm{~B}$ when particle size was increased from 120 to $250 \mu \mathrm{m}$ and also when groups $1 \mathrm{~A}$ and $1 \mathrm{~B}$ were compared with group 2 (Graph 2).

The mean marginal loss after finishing also showed statistically significant results when marginal loss in three margins were compared in groups $1 \mathrm{~A}$ and $1 \mathrm{~B}$. shoulder with bevel margin showed statistically significant marginal loss when compared with chamfer and shoulder margins with p-value $0.0000(\mathrm{p}<0.05)($ Graph 3). The marginal loss in chamfer margin was greater than shoulder but the difference was not statistically significant.

\section{DISCUSSION}

Air abrasion is a convenient and popular procedure used in dental laboratory which is routinely used during various 


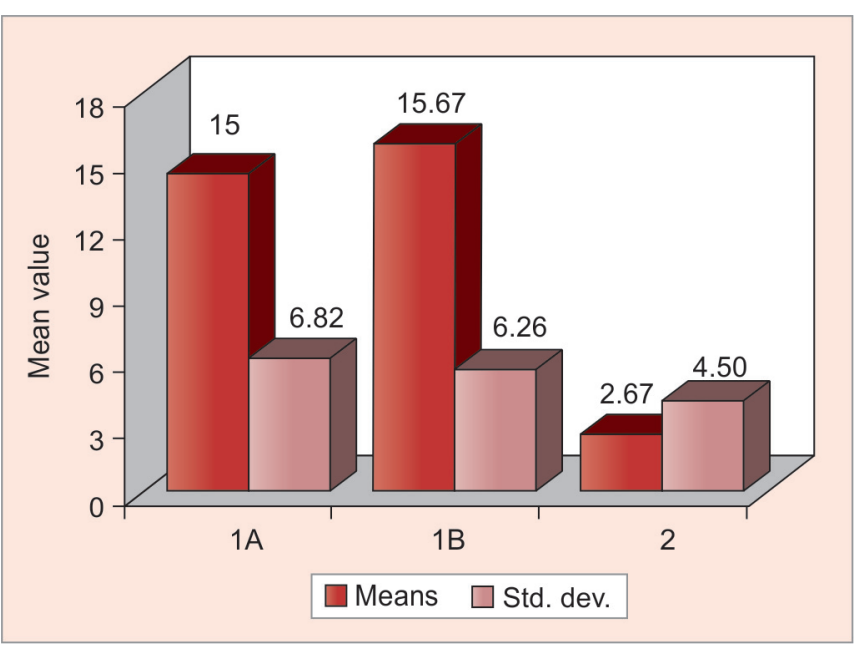

Graph 3: Comparison of group 1A, 1B and group 2 with marginal loss after finishing

procedures such as removal of retained phosphate bonded investment material, provide mechanical retention, and increase the surface area for chemical bonding of porcelain. However, during sandblasting the margins on the castings may be altered or significantly worn. The potential problems from this procedure have been suggested by several investigators. Michael A Mansueto ${ }^{2}$ reported about frequently encountered, irreparably damaged castings caused by unanticipated outcomes of sandblasting use.

Titanium and its alloys have gained popularity owing to excellent physical and biological properties like high strength, low weight, low density, passivity, biocompatibility, etc. ${ }^{8}$ However, the effect of air abrasion on titanium is an area where much research is needed. Felton and Kanoy ${ }^{1}$ in their study found out that the marginal abrasion ranged from 5 to $110 \mu \mathrm{m}$ during air abrasion of dental castings which can cause significant marginal damage.

The aim of this study was to evaluate the effect of air abrasion on marginal accuracy of titanium crowns after castings with three different types of marginal configurations. To clearly demonstrate damage, laboratoryrelevant testing conditions were used. $\mathrm{The}_{2} \mathrm{Al}_{2} \mathrm{O}_{3}$ particles were directed perpendicular to the samples edges, which represented the air abrasion exposure that the casting margins might experience during cleaning and preparation during divestment procedures. Pressure of 4 bars is a commonly used, low pressure setting on many sand blasting units. The 15 seconds exposure time and the $10 \mathrm{~mm}$ distance between the specimen and the abrader nozzle were established following observation of laboratory technicians who divested fixed partial dentures using air abrasion at various dental laboratories. The average time taken was 1 minute and 35 seconds. With an appreciation for the frequency and duration of air abrasion during a variety of other laboratory steps, 15 seconds exposure time appeared to be a reasonable test standard. Felton and Kanoy ${ }^{1}$ in their study found out that castings have a minimum exposure of 10 seconds to abrasive particles during air abrasion in dental laboratory.

A major factor affecting the vertical loss of alloy at the casting margin after air abrasion was the margin configuration when air abraded with 120 and $250 \mu \mathrm{m}$ aluminum oxide. The data showed maximum marginal loss in relation to shoulder with bevel margin and minimum loss with shoulder edge margin. Felton and Kanoy ${ }^{1}$ also reported similar results in relation to marginal loss in dental castings in relation to base metal alloys. Therefore although the vertical loss for the shoulder margin configuration was low, it still created a situation that clinically would generate a local $\mathrm{V}$ shaped margin opening. Any margin opening encourages recurrent caries if it is substantially larger than the typical 0.02 to $2 \mu \mathrm{m}$ size of oral bacteria. ${ }^{1}$ The same opening could also permit periodontal inflammation because it produces a local contour change that is irritating to soft tissues in contact with the margin subgingivally. ${ }^{1}$

Another major factor affecting the vertical marginal loss at the casting margins was the particle size of the abrasive, i.e. $\mathrm{Al}_{2} \mathrm{O}_{3}$. Abrasive particles have impact energy: they hit the surface and generate defects. The difference in marginal loss after air abrasion with 120 and $250 \mu \mathrm{m}$ aluminum oxide showed significant result when compared with ANOVA and student $t$ test with $p$ value $0.0000(p<0.05)$. There was also a statistically significant difference in marginal loss between groups $1 \mathrm{~A}$ and $1 \mathrm{~B}$ when particle size was increased from $120 \mu \mathrm{m}$ to $250 \mu \mathrm{m}$ and also when groups $1 \mathrm{~A}$ and $1 \mathrm{~B}$ were compared with group 2. Similar results were reported by Kern M, Thomson $\mathrm{VP}^{9}$ in their study on effect of sandblasting on pure titanium.

The titanium alloys have a high resistance to abrasion; thus they are more difficult to grind than the base metal and gold based alloys. ${ }^{10}$ The high hardness of these alloys presents a real problem at finishing stage. ${ }^{11,12}$ The mean marginal loss after finishing also showed statistically significant results when marginal loss in three margins were compared in groups $1 \mathrm{~A}$ and $1 \mathrm{~B}$. shoulder with bevel margin showed statistically significant marginal loss when compared with chamfer and shoulder margins with p-value 0.0000 $(p<0.05)$. The marginal loss in chamfer margin was greater than shoulder but the difference was not statistically significant.

The mean marginal loss in titanium in this study was similar to that reported for base metal alloys in previous studies. ${ }^{1,2}$ Kern M and Thomson VP 9 measured volume loss of titanium after sandblasting and compared it with base metal alloys and found no significant difference between 
titanium and base metal alloys. The present study showed the damage to casting margin when the particle size of air abrasive was increased from 120 to $250 \mu \mathrm{m}$ which should be a cause of concern for technicians and dentists who routinely expose dental castings to air abrasion and finishing. Since $20 \mu \mathrm{m}$ was the minimum mean marginal loss following air abrasion, it appears that margins exposed to relatively low pressure air abrasion are at risk for clinically significant damage. The damage caused due to air abrasion to the casting margins may cause casting distortions affecting the quality of fit of the restorations. ${ }^{13}$

Clinicians experiencing casting fit discrepancies should assess the use of air abrasion during laboratory procedures. The shoulder marginal configuration showed the least amount of vertical marginal loss after air abrasion and finishing, but clinically it would still create a local V shaped margin opening. Any margin opening encourages recurrent caries if it is larger than the typical 0.02 to $2 \mu \mathrm{m}$ size of the oral bacteria. The same opening could also permit periodontal inflammation because it produces a local contour change that is irritating to soft tissues in contact with the margin subgingivally. As more laboratory steps are supported by micro abrader use, effects of air abrasion will be cumulative. Awareness of the risk of air abrasion and its effects on dental castings will reduce the unnecessary damage to the castings. Safeguard measures to prevent damage to the castings due to air abrasion use include the selection of a particle with less mass, increased distance from the hand piece to the sample, shorter exposure time and covering the margin area with modeling wax.

\section{SUMMARY AND CONCLUSION}

The effects of aluminum oxide air abrasion were studied on castings with 20,45 and $90^{\circ}$ margin angles that were cast from commercially pure titanium. Air abrasion with aluminum oxide shortened all of the types of cast margins. The smaller the margin angle, the greater was the loss of alloy after air abrasion (shoulder with bevel $>$ chamfer $>$ shoulder). Particle size of the abrasive influenced the vertical marginal loss. As the particle size increased from 120 to $250 \mu \mathrm{m}$, marginal loss also increased. The mean marginal loss after finishing also showed statistically significant results when marginal loss in three margins were compared in groups $1 \mathrm{~A}$ and $1 \mathrm{~B}$. shoulder with bevel margin showed statistically significant marginal loss when compared with chamfer and shoulder margins. The marginal loss in chamfer margin was greater than shoulder but the difference was not statistically significant.

\section{REFERENCES}

1. Felton DA, Bayne SC, Kanoy BE, White JT. Effect of air abrasives on marginal configurations of porcelain fused to metal alloys: an SEM analysis. J Prosthet Dent1991;65:38-43.

2. Mansueto MA, Verrett RG, Phoenix RD. Microabrasion of cast metal margins - awarning. J Prosthodont 2007;16:136-140.

3. Carter JM, Al-Mudafar J, Sorensen SE. Adherence of a nickelchromium alloy and porcelain. J Prosthet Dent 1979;41: 167-172.

4. Carpenter MA, Goodkind RJ. Effect of varying surface texture on bond strength of one semiprecious and one nonprecious ceramoalloy. J Prosthet Dent1979;42:86-95.

5. Taga Y, Kawai K, Nokubi T. New method for divesting cobaltchromium alloycastings: sandblasting with a mixed abrasive powder. J Prosthet Dent 2001;85:357-362.

6. Kern M, Thompson VP. Effect of sandblasting and silica coating on dental alloys: volume loss, morphology and changes in the surface composition. Dent Mater 1993;9:155-161.

7. Wang RR, Fenton A. Titanium for prosthodontic applications: A review of literature. Quintessence Int 1996;27:401-408.

8. Watanabe I, Watanabe E, Yoshida K, Okabe T. Effect of surface contamination on adhesive bonding of cast pure titanium an Ti-6Al-4V alloy. J Prosthet Dent 1999;81:270-276.

9. Kern M, Thompson VP. Effect of sandblasting and silica coating procedures on pure titanium. J Dent 1994;22:300-306.

10. Guilherme AS, Henriques GE, Zavanelli RA, Mesquita MF. surface roughness and fatigue performance of commercially pure titanium and Ti-6Al-4Valloy after different polishing protocols. J Prosthet Dent 2005;93:378-385.

11. Reddy ES, Patil NP, Guttal SS, Jagdish HG. Effect of different finishing and polishing agents on the surface roughness of cast pure titanium. J Prosthodont 2007;16:263-268.

12. Guilherme AS, Henriques GE, Zavanelli RA, Mesquita MF. surface roughness and fatigue performance of commercially pure titanium and Ti-6Al-4 Valloy after different polishing protocols. J Prosthet Dent 2005;93:378-385.

13. DeHoff PH, Anusavice KJ. Effect of metal design on marginal distortion of metal ceramic crowns. J Dent Res 1984;63: 1327-1331.

\section{ABOUT THE AUTHORS}

\section{Bhupender Yadav (Corresponding Author)}

Senior Lecturer, Department of Prosthodontics, SGT Dental College, Gurgaon, Haryana, India, Phone: 8743019484, e-mail: yadav.prerna28@gmail.com

\section{Puja Malhotra}

Reader, Department of Prosthodontics, SGT Dental College, Gurgaon Haryana, India

\section{Ramesh Nadiger}

Professor, Department of Prosthodontics, SDM Dental College Bengaluru, Karnataka, India

\section{Harish Yadav}

Professor, Department of Prosthodontics, SGT Dental College Gurgaon, Haryana, India 